\title{
Managing Anemia across the Stages of Kidney Disease in Those Hyporesponsive to Erythropoiesis-Stimulating Agents
}

\author{
Matthew R. Weir \\ Division of Nephrology, University of Maryland Medical Center, Baltimore, MD, USA
}

\section{Keywords}

Anemia $\cdot$ Chronic kidney disease · Erythropoiesisstimulating agent hyporesponse $\cdot$ Hepcidin hypoxiainducible factor . Prolyl hydroxylase inhibitor

\begin{abstract}
Background: Patients with CKD frequently have anemia that results from iron-restricted erythropoiesis and inflammation. Anemia of CKD is currently managed with iron supplements and erythropoiesis-stimulating agents (ESAs) to promote erythropoiesis and with RBC transfusion in severe cases. Hyporesponse to ESAs, or the need for larger than usual doses to attain a given hemoglobin $(\mathrm{Hb})$ level, is associated with increased morbidity and mortality and presents a pressing clinical challenge, particularly for patients on dialysis. This paper reviews ESA hyporesponse and potential new therapeutic options in the management of anemia of CKD. Summary: The most common causes of ESA hyporesponse include iron deficiency and inflammation, and to a lesser degree, secondary hyperparathyroidism, inadequate dialysis, malnutrition, and concomitant medications. Management of ESA hyporesponse is multipronged and involves treating low level infections, ensuring adequate nutrition, and optimizing iron status and dialysis modality, although some patients can remain refractory. Inflammation directly increases production and secretion of hepcidin, contributes to an im-
\end{abstract} \\ Karger"}

paired response to hypoxia, and suppresses proliferation of erythroid progenitors. Coordination of renal and hepatic erythropoietin (EPO) production and iron metabolism is under the control of hypoxia-inducible factors (HIF), which are in turn regulated by HIF-prolyl hydroxylases (HIF-PHs). HIF$\mathrm{PHs}$ and hepcidin are therefore attractive potential drug targets particularly in patients with ESA hyporesponse. Several oral HIF-PH inhibitors have been evaluated in patients with anemia of CKD and have been shown to increase $\mathrm{Hb}$ and reduce hepcidin regardless of inflammation, iron status, or dialysis modality. These sustained effects are achieved through more modest increases in endogenous EPO compared with ESAs. Key Messages: Treatments that address ESA hyporesponse remain a significant unmet clinical need in patients with anemia of CKD. New therapies such as HIF-PH inhibitors have the potential to address fundamental aspects of ESA hyporesponse and provide a new therapeutic option in these patients.

(c) 2021 S. Karger AG, Basel

\section{Introduction}

Anemia is common in patients with CKD and is associated with increased morbidity and mortality [1-3]. Anemia of CKD results from low erythropoietin (EPO) production by the failing kidney [4] and immune activa- 
Table 1. Definitions of ESA hyporesponse

\begin{tabular}{ll}
\hline Source & Definition of ESA hyporesponse \\
\hline NKF-KDOQI [21] & 450 units/kg per week i.v. EPO or 300 units $/ \mathrm{kg}$ per week s.c. EPO \\
\hline KDIGO [11] & $\begin{array}{l}\text { No increase in Hb concentration from baseline after the first month of ESA treatment on } \\
\text { appropriate weight-based dosing }\end{array}$ \\
\hline $\begin{array}{l}\text { NICE best practices/The Renal } \\
\text { Association [18] }\end{array}$ & $\begin{array}{l}\text { Failure to reach the target Hb level despite s.c. epoetin dose }>300 \mathrm{IU} / \mathrm{kg} / \mathrm{week}(450 \mathrm{IU} / \mathrm{kg} / \mathrm{week} \text { i.v. } \\
\text { epoetin) or darbepoetin dose }>1.5 \mu \mathrm{gg} / \mathrm{keek}\end{array}$ \\
\hline ERI [16]/EHRI [22] & Weight-adjusted weekly ESA dose divided by the Hb value $>12.7-20.0 \mathrm{IU}$ weekly/kg/Hb, g/dL \\
\hline
\end{tabular}

NKF-KDOQI, National Kidney Foundation-Kidney Disease Outcomes Quality Initiative; KDIGO, Kidney Disease Improving Global Outcomes; EHRI, ESA hyporesponsiveness index; EPO, erythropoietin; ESA, erythropoiesis-stimulating agent; Hb, hemoglobin; ERI, ESA response index.

tion, which inhibits iron absorption and mobilization, suppresses EPO production, and decreases erythrocyte survival, all of which lead to iron-restricted erythropoiesis [5]. This pattern is now recognized as anemia of inflammation.

Anemia of CKD is currently managed with oral or intravenous (IV) iron and erythropoiesis-stimulating agents (ESAs) to promote erythropoiesis and with RBC transfusion in severe cases and as a last resort in most patients. However, in patients with cancer, per the American Society of Oncology and American Society of Hematology guidelines, transfusions are preferred to ESAs in those receiving myelosuppressive chemotherapy; ESAs are not recommended in most patients with non-chemotherapy-associated anemia or when myelosuppressive chemotherapy is anticipated to be curative [6].

Correction of anemia with the supplemental approach of iron and ESAs is effective in many patients and is associated with increased hemoglobin $(\mathrm{Hb})$ levels, reduced need for blood transfusions, improved exercise tolerance and health-related quality of life, and reductions in left ventricular mass [7-9]. However, dosing with ESAs to target normalized $\mathrm{Hb}$ levels (i.e., $\mathrm{Hb}$ target $\sim 13.5 \mathrm{~g} / \mathrm{dL}$ ) is associated with an increased incidence of adverse clinical outcomes (death, myocardial infarction, and hospitalization for congestive heart failure) $[10,11]$. As a result, use of ESAs to achieve $\mathrm{Hb}$ targets $>11.5 \mathrm{~g} / \mathrm{dL}$ is not recommended $[10,11]$. Rather, the current US Food and Drug Administration guidelines recommend considering the lowest approved effective dose of ESA.

Some patients do not respond to ESAs or require a larger than usual dose of ESA to attain a given $\mathrm{Hb}$ level. This condition, known as ESA hyporesponse or resistance, is associated with increased morbidity, mortality, and healthcare resource utilization [12-16], and is a pressing clinical challenge. The objective of this review is to (1) provide an overview of factors leading to ESA hyporesponse; (2) evaluate the clinical use of relatively high doses of ESAs, and (3) discuss the role of emerging therapeutics for the treatment of anemia of CKD in patients hyporesponsive to ESAs.

\section{Prevalence and Characteristics of ESA Hyporesponse}

There is no universally accepted definition of hyporesponse or resistance to an ESA (Table 1) [11, 17-22]. In practice, it often means failure to achieve a target $\mathrm{Hb}$ concentration despite receiving a higher than usual dose of a given ESA or a requirement for increasing doses of an ESA to maintain a target Hb level [20]. For epoetin alfa, the National Kidney Foundation-Kidney Disease Outcomes Quality Initiative (NKF-KDOQI) and National Institute for Health and Care Excellence (NICE) definitions for ESA hyporesponse equate to a dose greater than the maximum recommended starting dose (50-100 units/kg/ thrice weekly) $[17,21,23]$. Similarly, the NICE hyporesponse definition equates to a dose $>3$-fold the recommended starting dose for darbepoetin alfa $(0.45 \mu \mathrm{g} / \mathrm{kg} /$ week) $[21,24]$.

While it is believed that the majority of patients with CKD stages 3-5 have relative epoetin deficiency [25], ESA hyporesponse is less common and its incidence and prevalence vary widely depending on the characteristics of the population studied and the criteria used to define ESA hyporesponse. For example, recent estimates of prevalence range from $12.5 \%$ when both $\mathrm{Hb}$ level and ESA dose were included in the definition [26], to $30.3 \%$ when only 


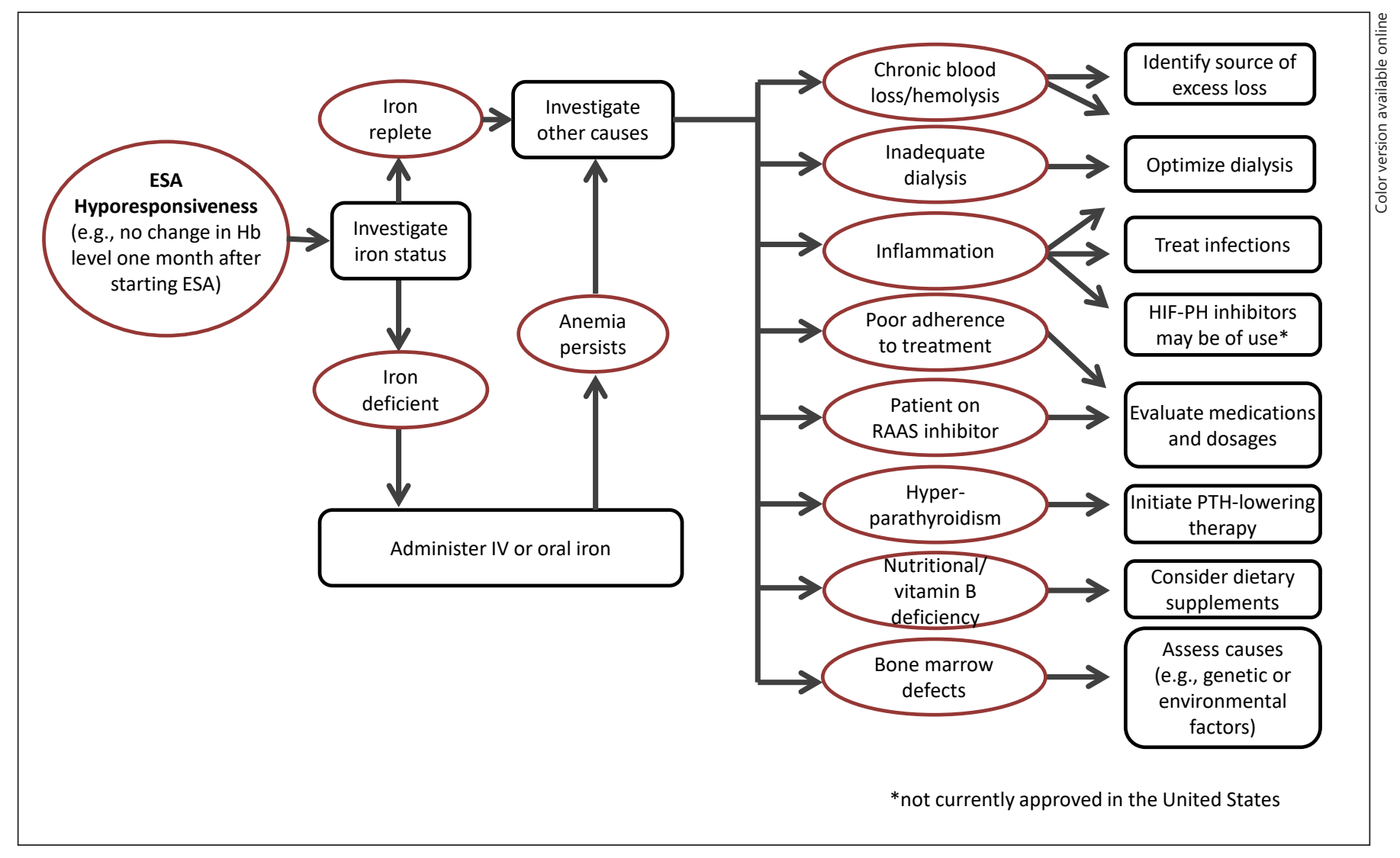

Fig. 1. Factors associated with ESA hyporesponse. ESA, erythropoiesis-stimulating agent; RAAS, renin-angiotensin-aldosterone system; HIF, hypoxia inducible factor; HIF-PH, HIF prolyl hydroxylase; PTH, parathyroid hormone.

change from baseline in $\mathrm{Hb}$ was considered in patients with baseline $\mathrm{Hb}<11 \mathrm{~g} / \mathrm{dL}$ [27]. Regardless of the definition, ESA hyporesponse is associated with increased allcause mortality in patients with CKD when compared with patients who respond as expected to ESAs [12, 13, $16,20,28-30]$. Moreover, poor response to ESAs has also been associated with adverse outcomes in patients with anemia of diabetic kidney disease [14], and with anemia in heart failure [31].

Dose escalation does not ameliorate anemia in patients who are hyporesponsive to ESAs. Indeed, use of high doses of ESAs may contribute to the adverse clinical outcomes as shown in the Correction of Hemoglobin and Outcomes in Renal Insufficiency (CHOIR) trial. Patients in CHOIR had CKD and a baseline $\mathrm{Hb}$ of $<11 \mathrm{~g} / \mathrm{dL}$ and were randomized to achieve a target $\mathrm{Hb}$ of 11.3 or $13.5 \mathrm{~g} / \mathrm{dL}$ with epoetin alfa dosed once weekly [32]. The incidence of the primary outcome (composite endpoint of death, congestive heart failure, stroke, and myocardial infarction) was significantly higher in patients assigned to the higher $\mathrm{Hb}$ target of $13.5 \mathrm{~g} / \mathrm{dL}$ [32]. Significantly, a secondary analysis that examined epoetin alfa dose as a potential contributor to these adverse outcomes showed that those patients who failed to achieve the assigned $\mathrm{Hb}$ target had higher event rates [33]. This trend was evident in both groups, and within each group, patients who received high epoetin alfa doses $(\geq 20,000 \mathrm{U})$ had higher event rates than patients who received low epoetin alfa doses $(<20,000 \mathrm{U})$ [33]. Inability to achieve the target $\mathrm{Hb}$ and use of high-dose epoetin alfa were each also significantly associated with increased risk of the primary endpoint, composite time to death, myocardial infarction, hospitalization for congestive heart failure, or stroke in unadjusted analyses [33]. However, in adjusted models, only high-dose epoetin alfa was associated with a significantly increased hazard of the primary end point, suggesting that the use of high doses of ESAs in the setting of ESA hyporesponse may do more harm than good [33]. In the Trial to Reduce Cardiovascular Events with Aranesp Therapy (TREAT) in patients with diabetes mellitus and moderate anemia of $\mathrm{CKD}$, 
treatment with darbepoetin alfa at a median monthly dose of $176 \mu \mathrm{g}$, designed to target a $\mathrm{Hb}$ level of $13.0 \mathrm{~g} / \mathrm{dL}$, was associated with a 2-fold increased risk of stroke compared with placebo [34]. An increased risk of stroke was similarly observed in the Reduction of Events by Darbepoetin Alfa in Heart Failure (RED-HF) trial in patients with heart failure who met the TREAT inclusion criteria [35]. Collectively, these observations suggest that the risks versus benefits of ESAs - especially high-dose ESA therapy needed to target higher Hb levels or address ESA hyporesponse - need to be carefully weighed.

The type of ESA may play a role in the risk of adverse outcomes, but the relative risk among individual ESAs remains controversial. In a large, long-term, randomized trial, patients with CKD receiving epoetin beta pegol had no increase in risk of all-cause mortality, nonfatal myocardial infarction, or stroke compared to those receiving either epoetin alfa or darbepoetin alfa [36], in agreement with prior meta-analyses that found no significant safety differences among ESAs [37-39]. A recent pooled analysis of prospective cohorts in Italy with non-dialysis-dependent (NDD) CKD stages 1-5 showed that the risk of the composite of end-stage kidney disease or death was not impacted by the type of ESA (e.g., short-acting [epoetin alfa or epoetin beta] or long-acting [darbepoetin alfa or epoetin beta pegol]) when all dosing levels were pooled but did increase at higher standardized ESA doses [40]. Notably, patients receiving high doses of short-acting ESAs had a 2 -fold increased risk of the composite endpoint compared with those receiving low short-acting ESA doses and a 56\% increased risk compared with those receiving high longacting ESA doses [40]. Conversely, a nationwide cohort study of 194,698 patients on dialysis in Japan found that the death rate was $13 \%$ higher in patients receiving longacting (darbepoetin alfa or epoetin beta pegol) versus those receiving short-acting (epoetin alfa, epoetin beta, or epoetin kappa) ESAs [41]. Reasons for these discrepancies remain unclear but could be related to differences in CKD severity (e.g., dialysis dependence vs. not) or regional and ethnic differences among study populations.

\section{Causes of ESA Hyporesponse}

Although disease severity and comorbidities may, in part, contribute to ESA hyporesponse, the most common causes include iron deficiency and inflammation, and to a smaller degree, secondary hyperparathyroidism (SHPT), inadequate dialysis, and concomitant medications (Fig. 1).

ESA Hyporesponsiveness

\section{Iron Deficiency}

Absolute iron deficiency in patients with CKD results from increased blood loss due to frequent blood draws, residual blood in hemodialysis tubing, and decreased dietary intake or reduced absorption of iron from the gastrointestinal tract $[42,43]$. Consequently, there is a severe reduction in the quantity of iron stored in the bone marrow, liver, and spleen, which is needed during periods of increased demand for $\mathrm{Hb}$ synthesis, for example, in response to treatment with ESAs [44]. Clinically, a transferrin saturation (TSAT, a measure of circulating iron) of $\leq 20 \%$ and serum ferritin (a marker of overall iron stores) of $\leq 100 \mathrm{ng} / \mathrm{mL}$ are diagnostic for absolute iron deficiency in patients with NDD-CKD or in those on peritoneal dialysis, while serum ferritin of $\leq 200 \mathrm{ng} / \mathrm{mL}$ is diagnostic for absolute iron deficiency in patients with CKD on hemodialysis [44]. Functional iron deficiency, or iron-restricted erythropoiesis, occurs when adequate bodily iron stores are present but release of iron from macrophages into the circulation is blocked due to inflammation and/ or increased hepcidin production $[45,46]$ or does not occur rapidly enough to support an increased rate of erythropoiesis, for example, during treatment with ESAs [47]. Hepcidin is produced by the liver and sequesters iron by traveling in the circulation and binding to ferroportin, the only known transmembrane iron exporter, on enterocytes, macrophages, and hepatocytes, causing its internalization and degradation $[48,49]$. Loss of transmembrane iron transport interrupts absorption and recycling of iron and promotes iron sequestration by preventing release from intracellular stores [46]. TSAT $\leq 20 \%$ and elevated serum ferritin levels $(>100 \mathrm{ng} / \mathrm{mL})$ are indicative of functional iron deficiency $[5,44]$. In a large, open-label, randomized controlled trial in patients with dialysis-dependent (DD)-CKD, proactive treatment with high-dose IV iron was associated with use of lower ESA doses and decreased the risk of hospitalizations, as compared with a low-dose, reactive IV iron regimen [50]. This supports the notion that correcting iron deficiency may improve ESA response, although whether any of the patients were hyporesponsive to ESAs was not reported [50]. However, in a retrospective study of patients with DD-CKD from the CROWNWeb database, a greater proportion (26.5\%) of patients who were hyporesponsive to ESAs had iron deficiency with TSAT $\leq 20 \%$ compared with $10.9 \%$ in those who responded normally to ESAs [16]. This occurred despite similar rates of IV iron use in the 2 months prior to meeting the hyporesponse criteria, suggesting IV iron therapy alone may not be sufficient to address ESA hyporesponse [16]. 


\section{Inflammation}

Inflammation is the common denominator in the anemia frequently observed in patients with chronic illnesses including CKD and contributes to an impaired response to hypoxia and ESA hyporesponse [5]. Low-level inflammation directly increases production and secretion of hepcidin by hepatocytes [45]. Specifically, signaling via inflammatory cytokines such as interleukin (IL)- $1 \beta$, tumor necrosis factor alpha (TNF- $\alpha$ ), and IL- 6 leads to increased hepcidin levels $[48,49]$. In patients with NDD$\mathrm{CKD}$, a positive correlation was shown between hepcidin level and ESA dose [51], and between hepcidin and the ESA response index (ERI, the average ratio of weight-adjusted ESA dose to $\mathrm{Hb}$ used as a measure of ESA hyporesponse; Table 1) [52]. Interestingly, markers of inflammation are also correlated with ESA resistance and anemia [27, 52-56]. IL-6 and C-reactive protein (CRP) levels are significantly higher in patients who are hyporesponsive to ESAs $[53,57]$, and IL-6 levels are a strong predictor of ESA resistance in patients on hemodialysis [57]. Moreover, in a recent study, patients on hemodialysis in the highest tertile of ERI had higher mean IL-6, high-sensitivity (hs) CRP, ferritin, and hepcidin levels and lower $\mathrm{Hb}$ levels, RBC counts, and hematocrit than patients in lower tertiles [56].

Regional and racial differences in inflammation and ESA dose have been reported. A recent longitudinal study of patients enrolled in the Dialysis Outcomes Practice Patterns Study found dialysis patients in Japan had lower median CRP levels ( 2 vs. $3 \mathrm{mg} / \mathrm{L}$ ) and lower mean weekly ESA doses (5,200 vs. 7,800 U/week) compared with those in Australia, New Zealand, and Europe [58]. Nevertheless, acute increases in inflammation increased ESA dose requirements and incidence of ESA hyporesponse in both populations [58]. These data suggest an intricate association between inflammation, hepcidin, and ESA hyporesponse. Currently, CRP level as a surrogate for systemic inflammation in dialysis patients is not measured in clinical practice in the USA [59].

The hypoxia-inducible factor (HIF) pathway plays a critical role in the normal physiologic response to hypoxia, including the upregulation of EPO [60]. In CKD, HIF is not activated as the reduced oxygen delivery to the kidney coupled with reduced kidney tissue oxygen consumption due to $\mathrm{CKD}$-induced structural and functional changes creates a pseudonormoxic state. This impairs production of endogenous EPO as the oxygen gradient is preserved despite reduced oxygen delivery to the kidney [61]. Inflammation may directly impair EPO production as IL- $1 \beta$ and TNF- $\alpha$ inhibit EPO transcription in vitro via the transcription factors NF- $\kappa \mathrm{B}$ and GATA-2 [62]. This is compounded by suppression of proliferation of erythroid progenitors by chronic inflammation in the hematopoietic microenvironment [63].

The most common causes of CKD are diabetes mellitus and/or hypertension [64], which are themselves common comorbidities and are associated with inflammation [65-67]. Interestingly, a recent retrospective study found that patients with DD-CKD who were hyporesponsive to ESAs had higher rates of hypertension and other cardiovascular diseases including heart failure, coronary heart/ artery disease, and arrhythmia, and higher rates of cardiovascular event-related hospitalizations prior to meeting the criteria for ESA hyporesponse, as compared with patients with a normal ESA response [16], further supporting a connection between inflammation-associated conditions and ESA hyporesponse.

\section{Secondary Hyperparathyroidism}

SHPT is a chronic condition characterized by elevated levels of parathyroid hormone (PTH). SHPT develops early in the course of $\mathrm{CKD}$, worsens as CKD progresses, and affects the majority of patients with advanced CKD, particularly those on dialysis [68-70]. Interestingly, there is an inverse correlation between PTH and Hb levels [71, 72], and elevated levels of PTH are significantly associated with ESA hyporesponse in patients on hemodialysis [73]. The exact mechanism(s) of anemia and ESA hyporesponse in SHPT remain unclear but may involve the suppression of endogenous EPO production by $\mathrm{PTH}$, as patients have been reported to have increased EPO levels after undergoing parathyroidectomy [74]. Similarly, patients receiving PTH-lowering therapies in several small studies showed improved $\mathrm{Hb}$ levels and, in some cases, were able to reduce their dose of ESA [75-77]. However, these effects were relatively modest or not evident in larger controlled trials [74]. Additionally, PTH may contribute to anemia by inducing fibrosis in bone marrow and decreasing RBC survival or production [74]. Finally, an observational study of patients with DD-CKD found increased risk of ESA hyporesponse in patients in the lowest $(5-440 \mathrm{pg} / \mathrm{mL})$ and highest $(8,621-76,000 \mathrm{pg} / \mathrm{mL})$ quintiles of fibroblast growth factor 23, a protein commonly dysregulated in SHPT [78].

\section{Concomitant Medications}

Drugs that inhibit the renin-angiotensin-aldosterone system (RAAS) are frequently used to treat comorbid hypertension; slow the progression of $\mathrm{CKD}$, particularly in patients with proteinuria; and improve cardiovascular 
outcomes [79]. Most trials have excluded patients with advanced CKD (estimated glomerular filtration rate $<30$ $\mathrm{mL} / \mathrm{min} / 1.73 \mathrm{~m}^{2}$ ) though evidence exists that RAAS inhibitors may also provide benefit in these patients [8082]. Treatment with RAAS inhibitors has been associated in a number of studies with ESA hyporesponse in patients with DD-CKD $[55,83]$, although 1 study showed no such association [84]. In cohorts of patients with NDD-CKD [85] or with CKD and predominantly not on dialysis [27], there are reports of both increased and decreased ESA hyporesponse in patients receiving RAAS inhibitors. Additionally, a study in patients with heart failure reported a protective effect of RAAS inhibitors on ESA responsiveness [31]. Due to the potential to inhibit erythropoiesis, RAAS inhibitor use should be carefully evaluated in patients hyporesponsive to ESAs. Pentoxifylline, a vasodilator, has been proposed as a potential treatment for ESA hyporesponse; however, in a small randomized, double-blind, placebo-controlled trial, patients treated with pentoxifylline had no significant improvement in ERI relative to those receiving placebo but did have modest relative increases in $\mathrm{Hb}(0.76 \mathrm{~g} / \mathrm{dL})$ [86]. In secondary analyses, pentoxifylline treatment was not associated with alterations to markers of oxidative stress [87] or significant reductions in hepcidin relative to placebo [88].

Interestingly, in patients with $\mathrm{DD}-\mathrm{CKD}$, treatment with statins has been suggested to ameliorate ESA hyporesponse [89-91]. In patients in predialysis, long-term statin therapy was inversely associated with ESA hyporesponse [92]. Likewise, an analysis of patients on hemodialysis showed that those receiving a statin had lower hsCRP levels than patients not on statins and a lower ERI and required lower ESA doses [90].

\section{Therapeutic Options and Strategies to Improve ESA Response}

\section{Management of Infection}

Management of anemia of CKD in patients who are hyporesponsive to ESAs involves a range of strategies (Fig. 1). Treating active infections, if present, and improving nutritional status are basic measures that may be helpful in all patients [93]. Dialysis catheters and nonfunctioning arteriovenous grafts may be a source of infection and inflammation and have been linked to ESA hyporesponse $[94,95]$.

\section{Optimization of Dialysis}

Optimizing dialysis is associated with reduction in inflammatory mediators, improved ERI, and improvements in response to ESAs [96-98]. For example, hemofiltration is associated with a more rapid decrease in ERI than low-flux bicarbonate dialysis [99] or high-flux hemodialysis [100]. Similarly, the use of ultrapure dialysate reduces ESA requirements, possibly associated with reduced inflammation $[101,102]$, while increased dialysis efficiency for small molecules is correlated with reductions both in hepcidin levels and ERI and, consequently, lower weekly ESA requirements $[99,103]$. Finally, increased dialysis time and/or frequency can be beneficial as switching from a conventional thrice weekly 3.5-4-h hemodialysis to three to five 8-h nocturnal sessions is associated with decreased ESA resistance [104].

\section{Correction of Iron Deficiency}

Iron deficiency is a notable cause of ESA hyporesponse [11]. A thorough assessment of iron status and correction of possible absolute or functional iron deficiency will ensure that any apparent ESA hyporesponse is real and not due to an easily corrected iron deficiency. As already discussed, in patients with DD-CKD, high-dose IV iron is not associated with an increased incidence of adverse clinical outcomes or infections and allows for lower ESA doses when compared with low-dose IV iron [50]. These recent data suggest that high-dose IV iron may be safe to administer and may lower ESA requirements. However, concerns remain regarding long-term use of high-dose IV iron [105], and iron administration does not address the fundamental mechanism that results in ESA hyporesponse.

Optimization of iron status, ESA dose, and dialysis parameters improves anemia in many patients; however, a proportion of patients remain refractory to ESAs and are in need of alternative therapies. Several novel drug classes that target the fundamental defects that lead to ESA hyporesponse are in development, including HIF-prolyl hydroxylase (HIF-PH) inhibitors and hepcidin antagonists.

\section{Targets for New Therapeutic Options}

\section{Hypoxia-Inducible Factor}

Coordination of renal and hepatic EPO production and iron metabolism is under the control of HIF [60]. HIF comprises 2 subunits (HIF- $\alpha$ and HIF- $\beta$ ) that dimerize in the nucleus and then bind to hypoxia response elements 


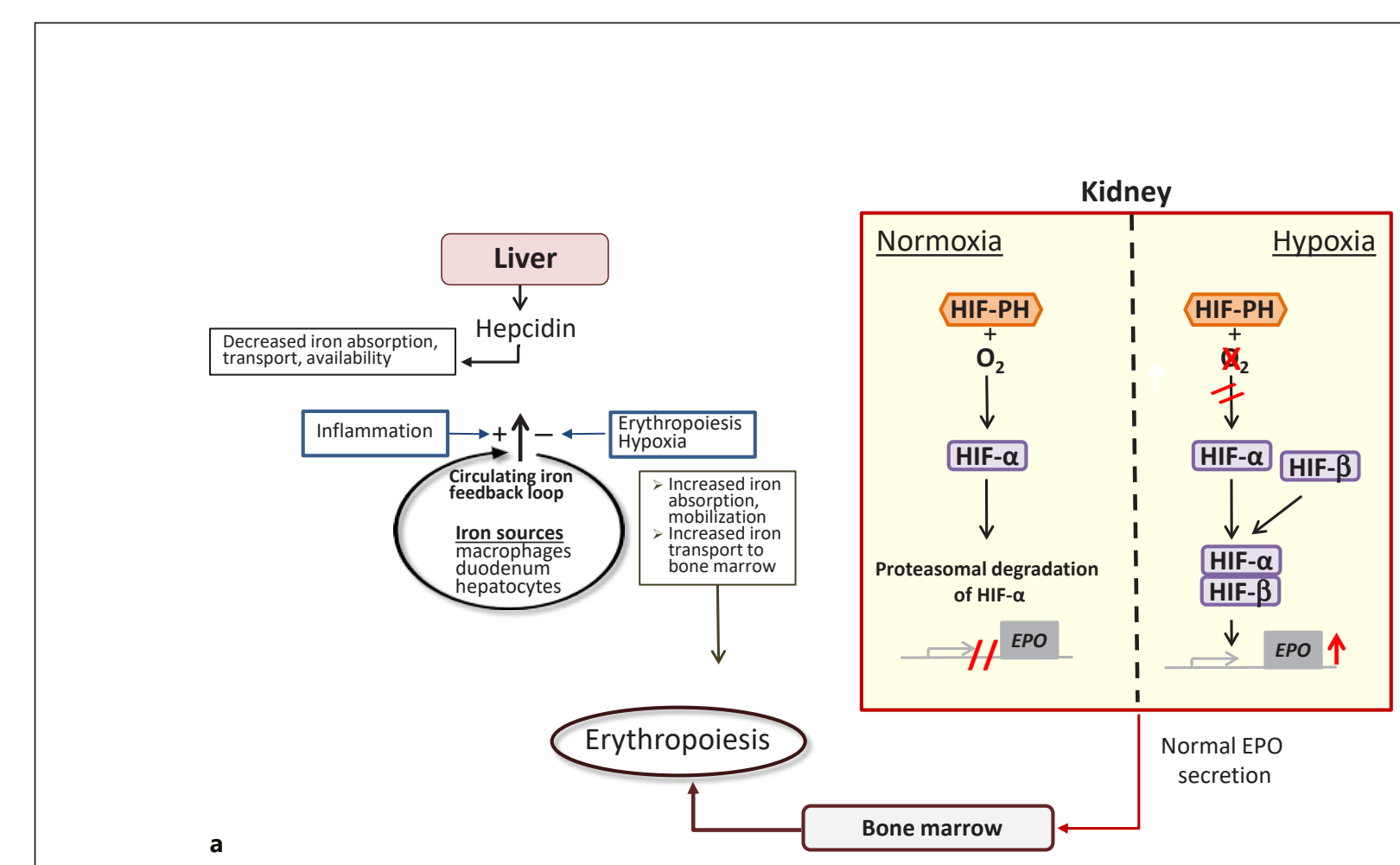


to induce transcription of many target genes, including the genes encoding EPO and its receptor [106, 107]. HIF- $\alpha$ is widely distributed in the cytoplasm and nucleus and bears 2 proline residues that are functional oxygen sensors [107]. Hydroxylation of one or both of these residues on HIF- $\alpha$ by HIF-PHs results in the binding of von Hippel-Lindau tumor suppressor protein, which marks the complex for rapid ubiquitination and proteasomal degradation [107]. HIF-PHs are exquisitely sensitive to changes in oxygen saturation, as small reductions in tissue oxygen levels reduce their enzymatic activity [108].

The oxygen-sensing properties of HIF-PHs are the key elements in regulating erythropoiesis. When oxygen delivery to tissues is sufficient (i.e., under normoxic conditions; Fig. 2), these enzymes are active, HIF- $\alpha$ is rapidly degraded before it can dimerize with HIF- $\beta$, and as a result, EPO gene transcription does not occur [60]. In contrast, HIF-PHs are inactive under hypoxic conditions; thus, HIF- $\alpha$ remains available to interact with HIF- $\beta$ and a cascade of events results in coordinated erythropoiesis $[60,109]$, including production of EPO in the kidney and the expression of proteins, which facilitate iron absorption by enterocytes such as divalent metal transporter 1 and duodenal cytochrome B reductase [4].

\section{HIF-PH Inhibitors}

It follows that inactivation of HIF-PHs will allow HIF- $\alpha$ and HIF- $\beta$ to dimerize in the nucleus, bind to hypoxia response element, induce gene expression, and ultimately stimulate production of endogenous EPO, improve iron metabolism, and promote erythropoiesis [110]. Accordingly, HIF-PHs represent an attractive therapeutic target and several orally administered HIF-PH inhibitors have been developed and evaluated in patients

Fig. 2. Hypoxia, HIF, and regulation of erythropoiesis. a In a normally functioning kidney, HIF-PHs sense and utilize oxygen $\left(\mathrm{O}_{2}\right)$ to promote the rapid degradation of the HIF- $\alpha$ subunit of the HIF transcription factor and EPO is not expressed. Hepcidin expression by the liver is minimal. When hypoxia occurs, HIF-PHs become inactive, allowing the HIF- $\alpha$ subunit to dimerize with the HIF- $\beta$ subunit to promote the expression of EPO, resulting in coordinated erythropoiesis. $\mathbf{b}$ In anemia of CKD, the normal oxygen gradient persists due to adaptive changes that result in reduced kidney oxygen delivery and consumption. This prevents activation of the HIF pathway and, coupled with damage to renal tubular fibroblasts, prevents appropriate increases in EPO. This is exacerbated by suppression of EPO transcription by inflammatory cytokines such as IL- $1 \beta$ and TNF- $\alpha$. Furthermore, IL- $1 \beta$, TNF- $\alpha$, and IL-6 stimulate production of the peptide hepcidin in the liver, which reduces the expression of the iron exporter FPN on the surface of many tissues, including macrophages and in the duode- with anemia of CKD, including those patients with NDDCKD and DD-CKD. Five agents in this class (roxadustat, daprodustat, vadadustat, molidustat, and enarodustat) have been approved in China and Japan for the treatment of anemia of CKD [60, 111-114].

Collectively, data from clinical trials of HIF-PH inhibitors, namely roxadustat [115-127], daprodustat [128135], desidustat [136], enarodustat $[137,138]$, molidustat [139-143], and vadadustat [144-149], have clearly shown these agents are efficacious in increasing $\mathrm{Hb}$ and decreasing hepcidin levels in patients with anemia of CKD (Table 2). Indeed, a recent meta-analysis of 22 trials found that HIF-PH inhibitors provided a 0.96 and $1.78 \mathrm{~g} / \mathrm{dL}$ greater weighted mean increases of $\mathrm{Hb}$ levels from baseline compared with control (placebo or ESA) in patients with DD-CKD or NDD-CKD, respectively [150]. Moreover, in 21 studies that measured serum hepcidin, HIF$\mathrm{PH}$ inhibitors led to a $40.42 \mu \mathrm{g} / \mathrm{L}$ greater weighted mean reduction in hepcidin relative to controls [150].

In patients with anemia of CKD not receiving ongoing ESA therapy, treatment with daprodustat was associated with increases in $\mathrm{Hb}$ concentration, decreases in serum hepcidin levels, and either increases [128] or no change in endogenous EPO levels [131]. Additionally, several studies have shown that $\mathrm{Hb}$ levels remain stable after switching from ongoing ESA therapy to treatment with an oral HIF-PH inhibitor [131, 140, 144-146]. In a phase 2 study of patients with DD-CKD and receiving ESA therapy, switching to oral roxadustat was associated with increased $\mathrm{Hb}$ levels and decreased hepcidin levels and promoted EPO levels in the physiologic range [117]. Mean $\mathrm{Hb}$ levels were maintained or increased in a dose-dependent manner during roxadustat treatment despite lower EPO levels than those observed with ESAs.

num, limiting the availability of iron for erythropoiesis. At the same time, diminished kidney function reduces the clearance of hepcidin, contributing to its accumulation in the circulation, thus further restricting iron. Collectively, this reduces erythropoiesis. Administration of ESAs mimics the function of EPO and directly stimulates erythropoiesis in the bone marrow but have minimal impact on iron homeostasis. On the other hand, HIF-PH inhibitors increase HIF- $\alpha$ and activate the HIF pathway and thus lead to production of endogenous EPO. Additionally, HIF-PH inhibitors indirectly suppress hepcidin expression, which restores FPN activity and allows mobilization of iron from internal stores. Red arrows denote changes brought about by CKD and inflammation, and green arrows denote effects of HIF-PH inhibitors. HIF, hypoxia inducible factor; HIF-PH, HIF prolyl hydroxylase; EPO, erythropoietin; IL, interleukin; TNF- $\alpha$, tumor necrosis factor alpha; FPN, ferroportin; ESAs, erythropoiesis-stimulating agents. 


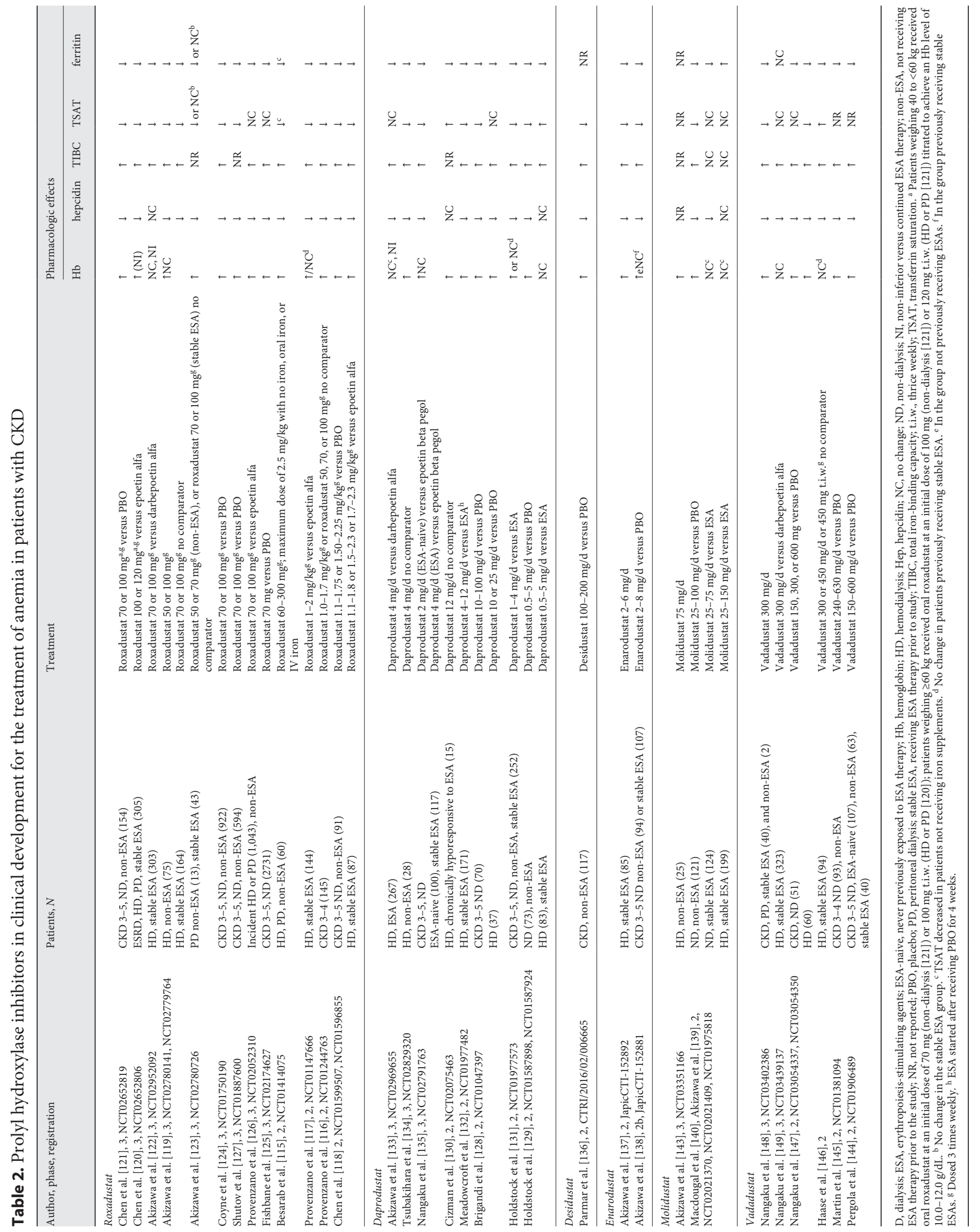


$\mathrm{Hb}$ levels improved with roxadustat treatment in each of 2 phase 3 trials in patients with CKD in China, including patients with NDD-CKD and DD-CKD. In patients with anemia of NDD-CKD not receiving ESAs, roxadustat produced significantly greater increases in $\mathrm{Hb}$ than placebo [121], and in patients with DD-CKD receiving stable ESA therapy at baseline, roxadustat therapy was non-inferior to continuing ESA therapy [120]. Recent global, long-term studies have corroborated these findings. In a phase 3 randomized, double-blind trial of 922 patients with NDD-CKD in the USA, South America, New Zealand, Australia, and Asia, patients receiving roxadustat had a least-squares mean increase in $\mathrm{Hb}$ that was $1.85 \mathrm{~g} / \mathrm{dL}$ greater than those receiving placebo [124]. A phase 3 study of 1,043 patients with CKD on dialysis for $>2$ weeks and $\leq 4$ months found similar mean increases in $\mathrm{Hb}$ in patients treated with roxadustat $(2.57 \mathrm{~g} / \mathrm{dL})$ compared with epoetin alfa $(2.36 \mathrm{~g} / \mathrm{dL})$ [126]. Preliminary analyses of 3 phase 3 trials in patients with NDDCKD found those treated with roxadustat had consistent, significant improvements in $\mathrm{Hb}$ ranging from 1.8 to 2.0 $\mathrm{g} / \mathrm{dL}$ compared with placebo $(0.2-0.4 \mathrm{~g} / \mathrm{dL})$ irrespective of geographic location [151]. Furthermore, 96.4 and $99.0 \%$ of patients receiving roxadustat had $\mathrm{Hb}>10.0 \mathrm{~g} / \mathrm{dL}$ after 6 and 12 months of treatment, respectively [152].

Similar findings have been observed in phase 3 studies of other HIF-PH inhibitors. For example, in patients with DD-CKD in Japan, daprodustat was non-inferior to darbepoetin alfa in maintaining $\mathrm{Hb}$ levels when switched from stable ESA [133], and in 2 global studies in patients on incident or maintenance dialysis, vadadustat was noninferior to darbepoetin alfa [153]. Likewise, interim (36 weeks) analysis of phase 3 studies in patients with NDD$\mathrm{CKD}$ in Japan showed molidustat to be non-inferior to darbepoetin alfa in maintaining [141] or improving [142] $\mathrm{Hb}$ levels in patients who converted from stable ESA or who were ESA-naive, respectively.

In patients with NDD-CKD with evidence of systemic inflammation, as indicated by elevated CRP levels, the baseline ESA dose was positively correlated with baseline CRP level [117], which is notable as inflammation is a suspected contributor to ESA hyporesponse. After switching from ESA therapy to roxadustat, $\mathrm{Hb}$ increases were independent of the baseline CRP level, and the average weekly dose required to maintain $\mathrm{Hb}$ levels was independent of baseline CRP level $[117,120]$. In contrast, among patients who continued ESA therapy, Hb levels were consistently lower in patients with elevated CRP levels, despite receiving consistently higher ESA doses [120]. Preliminary analysis of recent global phase 3 trials has rein- forced these findings as treatment with roxadustat resulted in similar increases in $\mathrm{Hb}$ across hsCRP concentration quintiles both in patients with DD-CKD (1.18$1.36 \mathrm{~g} / \mathrm{dL})$ [154] and NDD-CKD (1.90-1.96 g/dL) [155]. These results suggest that patients with anemia of CKD respond to roxadustat regardless of inflammatory status, providing a clear differentiation from ESAs. Furthermore, hepcidin levels decreased in patients randomized to roxadustat $[120,121]$, whereas there was no change in hepcidin levels in patients on placebo or ESA therapy. Reductions in hepcidin and improvements in $\mathrm{Hb}$ have been observed regardless of baseline CRP level and with or without iron supplementation [115]. In patients randomized to roxadustat alone, or with either oral or IV iron, the largest decreases in hepcidin levels occurred in those patients who received no exogenous iron, suggesting patients with $\mathrm{DD}$-CKD may not require IV iron therapy during roxadustat treatment [115]. In phase 3 studies, decreased hepcidin with roxadustat was coincident with mean increases in total iron-binding capacity from baseline $(18.2 \mu \mathrm{mol} / \mathrm{L}$ in patients with NDD-CKD and 10.0 $\mu \mathrm{mol} / \mathrm{L}$ in DD-CKD) and mean decreases in serum ferritin $(-93 \mu \mathrm{g} / \mathrm{L}$ in NDD-CKD and $-119 \mu \mathrm{g} / \mathrm{L}$ in DDCKD) from baseline, and similar improvements in iron parameters have been observed among multiple HIF-PH inhibitors (Table 2) [120, 121]. Collectively, these data suggest HIF-PH inhibitors improve iron homeostasis and may ameliorate functional iron deficiency.

The efficacy of HIF-PH inhibitors specifically in patients hyporesponsive to ESAs has been evaluated in a few instances. In a small phase 2 study, treatment with daprodustat for 12 weeks resulted in an increase or maintenance of $\mathrm{Hb}$ in the target range of $10.5-11.0 \mathrm{~g} / \mathrm{dL}$ in $40 \%$ of patients chronically hyporesponsive to ESAs [130]. Interestingly, in a phase 3 trial, patients with DD-CKD in the highest tertile of ERI received a median weekly dose of darbepoetin alfa of $25.8 \mu \mathrm{g} /$ week compared with $10.4 \mu \mathrm{g} /$ week in the lowest ERI tertile; however, in patients randomized to daprodustat, the median daily dose was similar, 4 and 6 $\mathrm{mg} /$ day, between the lowest and highest ERI tertiles, respectively [133]. In preliminary analysis of an uncontrolled study of 64 patients on hemodialysis who were resistant to ESAs, treatment with roxadustat was associated with a slight increase in $\mathrm{Hb}$ and a significant decrease in PTH, a suspected contributor to ESA hyporesponse, after 8 weeks [156]. Among patients without diabetes in the study, conversion to roxadustat was also associated with an increase in $\mathrm{Hb}$ from 10.3 to $10.7 \mathrm{~g} / \mathrm{dL}$ [157].

The safety of HIF-PH inhibitors is an area of ongoing investigation, including assessment of cardiovascular 
outcomes and all-cause mortality. An analysis of 18 trials found no difference in the risk of adverse events or severe adverse events between HIF-PH inhibitors and controls (placebo or ESA) [150]. Despite this, concerns related to hyperkalemia, hypertension, thromboembolism, and comorbid malignancy or cardiovascular events persist owing to inconclusive evidence from trials to date or theoretical consequences of HIF activation [158]. Whether select adverse events are specific to individual HIF-PH inhibitors or are common to the class remains an open question and awaits future publications and/or data.

Data pertaining to the effects of treatment with an HIF$\mathrm{PH}$ inhibitor on hard outcomes continue to emerge. In a single study of 836 patients on maintenance dialysis in central Europe, all-cause mortality was $15.4 \%$ with roxadustat and $12.1 \%$ with epoetin alfa or darbepoetin alfa [159]. Recently reported phase 3 studies in patients with NDD-CKD stages 3-5 found no significant difference in the risk of mortality [124] or in the incident mortality rate [127] in patients treated with roxadustat compared with placebo. In a phase 3 study of patients on dialysis $>2$ weeks and $\leq 4$ months, the number of fatal treatment-emergent adverse events was similar between the roxadustat and epoetin alfa groups [126]. Recently, vadadustat did not meet the outcome of non-inferiority in time to first major adverse cardiovascular event (a composite of death, myocardial infarction, and stoke) versus darbepoetin alfa in patients with NDD-CKD [160], but was non-inferior to darbepoetin alfa in time to first major adverse cardiovascular event in patients with DD-CKD [153].

While HIF transcription factors regulate numerous biological processes including angiogenesis, glucose and cholesterol metabolism, and cell growth, motility, and death $[60,161,162]$, adverse effects related to these processes have not been observed. Long-term safety of HIFPH inhibitors beyond phase 3 trials, including non-erythropoietic effects, remains to be determined, and the comparative efficacy, safety, and cost-effectiveness of HIF-PH inhibitors relative to ESAs remain areas of active investigation [163].

\section{Hepcidin Antagonists}

Hepcidin is an attractive target in anemia of inflammation because elevated hepcidin levels are associated with iron sequestration and anemia [5]. Several hepcidin antagonists have been evaluated in humans. Single intravenous infusions of an anti-hepcidin l-oligoribonucleotide (lexaptepid, NOX-H94) suppressed hepcidin activity and prevented inflammation-associated iron sequestration in healthy volunteers [164]. In a subsequent study in healthy volunteers, lexaptepid produced dose-dependent increases in serum iron concentration, serum ferritin, and TSAT after single and multiple IV doses [165].

Alternative strategies to block the effects of hepcidin include preventing its expression or interaction with ferroportin since hepcidin itself may be difficult to target due to its relatively high circulating levels and high turnover rate [166]. To these ends, monoclonal antibodies that target ferroportin (LY2928057) and bone morphogenetic protein 6 (LY3113593), a key regulator of hepcidin expression, have been developed. Their use increased serum iron and TSAT in healthy volunteers, and LY3113593 led to decreased hepcidin levels [166]. In phase 1 studies in patients with CKD, these antibodies either slowed the decline (LY2928057) or increased (LY3113593) Hb levels and both decreased ferritin relative to placebo [166]. Improvements in iron status appeared greater with LY2928057 than with LY3113593 in patients with CKD; however, the study of LY2928057 did not meet the prespecified threshold for $\mathrm{Hb}$ efficacy, suggesting the agent may not be effective as monotherapy. Lexaptepid and LY2928057 increased serum hepcidin concentrations, which is of concern in patients with CKD as increased hepcidin expression is associated with CV events [165167]. Potentially as a result of these considerations, the development of these agents appears to have been discontinued and their future remains unclear.

\section{Considerations in Light of Coronavirus Disease 2019}

Accumulating evidence from studies of SARS-CoV-2, the novel virus that caused the ongoing coronavirus disease 2019 (COVID-19) pandemic, shows that older patients and those with chronic illnesses such as CKD are at increased risk of infection, severity of disease, and mortality $[168,169]$. An analysis of data from 257 critically ill patients in 2 New York City hospitals found that critically ill patients with COVID-19 had a median age of 62 years and that $82 \%$ had at least one chronic illness, while $14 \%$ had CKD [170]. Moreover, severe COVID-19 is characterized by a hyperinflammatory state and an observational study reported COVID-19 is associated with iron deficiency and hyperferritinemia that appear to persist up to 2 months after COVID-19 onset [171]. The vulnerability of patients with CKD, especially those on traditional hemodialysis requiring 3 times weekly visits to a dialysis center, is evident and self-isolation is necessary to reduce the risk of COVID-19 transmission [172-174]. Similarly, patients with anemia of CKD receiving IV iron 
or an ESA require visits to an infusion center and are thus at higher risk of transmission. Treatment options that reduce the need for inter-person contact would be particularly valuable under such circumstances. Moreover, it has recently been suggested that ESAs may provide little benefit in patients with COVID-19 due to increased inflammation, but the full scope of this remains to be determined [175]. Here, orally administered alternatives to ESAs such as HIF-PH inhibitors and home dialysis modalities present strategies that could improve outcomes and alleviate the burden on patients with anemia of CKD and healthcare resources during crises.

\section{Limitations}

This review is limited by factors common to emerging therapies. As HIF-PH inhibitors are a relatively new class of therapeutic agents, there are discrepancies in the number of published studies among the various HIF-PH inhibitors. Further, data on patients hyporesponsive to ESAs are limited in part because these patients collectively carry a high disease burden and are often excluded from studies. Despite these limitations, multiple lines of indirect evidence suggest HIF-PH inhibitors should be explored further in this difficult-to-treat patient population.

\section{Conclusions}

ESA hyporesponse is associated with poor outcomes in patients with anemia of CKD. The use of high doses of ESA may be an underlying reason for increased morbidity and mortality. Disturbed iron homeostasis and inflammation are major contributors to the etiology of anemia in patients with CKD and may largely be responsible for ESA hyporesponse. Clinicians should therefore strive to eliminate sources of inflammation and infection, ensure adequate dialysis and nutrition, and correct absolute and functional iron deficiency in patients with ESA hyporesponse. Novel agents such as HIF-PH inhibitors and hepcidin antagonists, which address the fundamental defects that give rise to inflammatory anemia, are in clinical development. Although no studies to date have evaluated their efficacy specifically in patients hyporesponsive to ESAs, several lines of evidence suggest that HIF-PH inhibitors may offer advantages to these patients. Treatment with HIF-PH inhibitors is associated with increased $\mathrm{Hb}$ levels and improved iron metabolism, including decreased hepcidin levels, regardless of inflammation, iron status, or dialysis modality; effects mediated through modest increases in endogenous EPO levels and improved iron mobilization and absorption. Accordingly, these agents appear to represent feasible therapeutic options for patients with anemia of CKD and may be particularly useful in patients hyporesponsive to ESAs.

\section{Acknowledgements}

Brian Woolums, PhD, and Meri Pozo, PhD, CMPP of inScience Communications (New York, NY, USA), provided editorial support funded by AstraZeneca.

\section{Statement of Ethics}

The manuscript was developed in compliance with the Good Publication Practice 3 (GPP3) guidelines.

\section{Conflict of Interest Statement}

M.R.W. serves as a scientific advisor to AstraZeneca; Boehringer Ingelheim; Janssen Pharmaceuticals, Inc.; Merck Sharp \& Dohme; Otsuka Pharmaceutical Co.; and Vifor Pharma.

\section{Funding Sources}

The development of the manuscript was supported by AstraZeneca.

\section{Author Contributions}

The author meets the International Committee of Medical Journal Editors (ICMJE) criteria for authorship for the manuscript and takes responsibility for the integrity of the work as a whole. The author had full editorial control of the manuscript and provided his final approval of all content. The author has not received funding for this work.

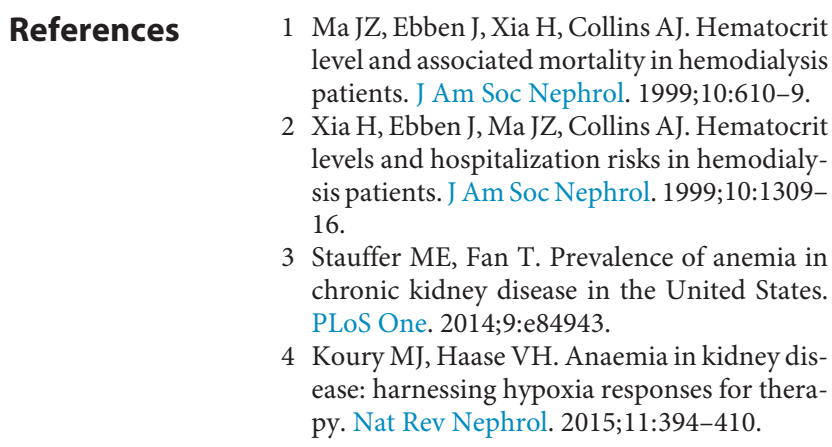


5 Weiss G, Ganz T, Goodnough LT. Anemia of inflammation. Blood. 2019;133:40-50.

6 Bohlius J, Bohlke K, Castelli R, Djulbegovic B, Lustberg MB, Martino M, et al. Management of cancer-associated anemia with erythropoiesis-stimulating agents: ASCO/ASH clinical practice guideline update. J Clin Oncol. 2019; 37:1336-51.

7 Association between recombinant human erythropoietin and quality of life and exercise capacity of patients receiving haemodialysis. Canadian Erythropoietin Study Group. BMJ. 1990;300:573-8.

8 Beusterien KM, Nissenson AR, Port FK, Kelly M, Steinwald B, Ware JE Jr. The effects of recombinant human erythropoietin on functional health and well-being in chronic dialysis patients. J Am Soc Nephrol. 1996;7:76373.

9 Parfrey PS, Lauve M, Latremouille-Viau D, Lefebvre P. Erythropoietin therapy and left ventricular mass index in CKD and ESRD patients: a meta-analysis. Clin J Am Soc Nephrol. 2009;4:755-62.

10 U.S. Food and Drug Administration. FDA Drug Safety Communication: modified dosing recommendations to improve the safe use of Erythropoiesis-Stimulating Agents (ESAs) in chronic kidney disease. 2011. Available from: https://www.fda.gov/drugs/drug-safety-and-availability/fda-drug-safety-communication-modified-dosing-recommendations-improve-safe-use-erythropoiesis.

11 Kidney Disease: Improving Global Outcomes (KDIGO) Anemia Work Group. KDIGO clinical practice guideline for anemia in chronic kidney disease. Kidney Int Suppl. 2012;2:279-335.

12 Kilpatrick RD, Critchlow CW, Fishbane S, Besarab A, Stehman-Breen C, Krishnan M, et al. Greater epoetin alfa responsiveness is associated with improved survival in hemodialysis patients. Clin J Am Soc Nephrol. 2008;3:1077-83.

13 Bradbury BD, Danese MD, Gleeson M, Critchlow CW. Effect of Epoetin alfa dose changes on hemoglobin and mortality in hemodialysis patients with hemoglobin levels persistently below $11 \mathrm{~g} / \mathrm{dL}$. Clin J Am Soc Nephrol. 2009;4:630-7.

14 Solomon SD, Uno H, Lewis EF, Eckardt KU, Lin J, Burdmann EA, et al. Erythropoietic response and outcomes in kidney disease and type 2 diabetes. N Engl J Med. 2010;363:114655.

15 Bae MN, Kim SH, Kim YO, Jin DC, Song HC, Choi EJ, et al. Association of erythropoietinstimulating agent responsiveness with mortality in hemodialysis and peritoneal dialysis patients. PLoS One. 2015;10:e0143348.

16 Cizman B, Smith HT, Camejo RR, Casillas L, Dhillon $\mathrm{H}, \mathrm{Mu}$ F, et al. Clinical and economic outcomes of erythropoiesis-stimulating agent hyporesponsiveness in the post-bundling era. Kidney Med. 2020;2:589-e1.

17 National Kidney Foundation-Kidney Disease Outcomes Qualtity Initiative. IV. NKF-KDOQI clinical practice guidelines for anemia of chronic kidney disease: update 2000. Am J Kidney Dis. 2001;37:S182-238.

18 Kliger AS, Foley RN, Goldfarb DS, Goldstein SL, Johansen K, Singh A, et al. KDOQI US commentary on the 2012 KDIGO clinical practice guideline for anemia in CKD. Am J Kidney Dis. 2013;62:849-59.

19 Rosati A, Tetta C, Merello JI, Palomares I, Perez-Garcia R, Maduell F, et al. Cumulative iron dose and resistance to erythropoietin. J Nephrol. 2015;28:603-13.

20 Sibbel SP, Koro CE, Brunelli SM, Cobitz AR. Characterization of chronic and acute ESA hyporesponse: a retrospective cohort study of hemodialysis patients. BMC Nephrol. 2015; $16: 144$.

21 Mikhail A, Brown C, Williams JA, Mathrani V, Shrivastava R, Evans J, et al. Renal association clinical practice guideline on anaemia of chronic kidney disease. BMC Nephrol. 2017; 18:345.

22 Rosati A, Ravaglia F, Panichi V. Improving erythropoiesis stimulating agent hyporesponsiveness in hemodialysis patients: the role of hepcidin and hemodiafiltration online. Blood Purif. 2018;45:139-46.

23 Epogen (epoetin alfa) US Prescribing Information. Thousand Oaks, CA: Amgen Inc.; 2017. Available from: https://www.pi.amgen.com/ / media/amgen/repositorysites/pi-amgen-com/ epogen/epogen_pi_hcp_english.pdf.

24 Aranesp (darbepoetin alfa) US Prescribing Information. Thousand Oaks, CA: Amgen Inc; 2018. Available from: https://www. pi.amgen.com/ /media/amgen/repositorysites/pi-amgen-com/aranesp/ckd/aranesp_ pi_hcp_english.pdf.

25 Artunc F, Risler T. Serum erythropoietin concentrations and responses to anaemia in patients with or without chronic kidney disease. Nephrol Dial Transplant. 2007;22: $2900-8$.

26 Luo J, Jensen DE, Maroni BJ, Brunelli SM. Spectrum and burden of erythropoiesis-stimulating agent hyporesponsiveness among contemporary hemodialysis patients. Am J Kidney Dis. 2016;68:763-71.

27 Ingrasciotta Y, Lacava V, Marcianò I, Giorgianni F, Tripepi G, D’ Arrigo G, et al. In search of potential predictors of erythropoiesisstimulating agents (ESAs) hyporesponsiveness: a population-based study. BMC Nephrol. 2019;20:359.

28 Zhang Y, Thamer M, Stefanik K, Kaufman J, Cotter DJ. Epoetin requirements predict mortality in hemodialysis patients. Am J Kidney Dis. 2004;44:866-76.

29 Kainz A, Mayer B, Kramar R, Oberbauer R. Association of ESA hypo-responsiveness and haemoglobin variability with mortality in haemodialysis patients. Nephrol Dial Transplant. 2010;25:3701-6.

30 Okazaki M, Komatsu M, Kawaguchi H, Tsuchiya K, Nitta K. Erythropoietin resistance index and the all-cause mortality of chronic hemodialysis patients. Blood Purif. 2014;37:106-12.
31 van der Meer P, Grote Beverborg N, Pfeffer MA, Olson K, Anand IS, Westenbrink BD, et al. Hyporesponsiveness to darbepoetin alfa in patients with heart failure and anemia in the RED-HF Study (Reduction of Events by Darbepoetin Alfa in Heart Failure): clinical and prognostic associations. Circ Heart Fail. 2018; 11:e004431.

32 Singh AK, Szczech L, Tang KL, Barnhart H, Sapp S, Wolfson M, et al. Correction of anemia with epoetin alfa in chronic kidney disease. N Engl J Med. 2006;355:2085-98.

33 Szczech LA, Barnhart HX, Inrig JK, Reddan DN, Sapp S, Califf RM, et al. Secondary analysis of the CHOIR trial epoetin-alpha dose and achieved hemoglobin outcomes. Kidney Int. 2008;74:791-8.

34 Pfeffer MA, Burdmann EA, Chen CY, Cooper ME, de Zeeuw D, Eckardt KU, et al. A trial of darbepoetin alfa in type 2 diabetes and chronic kidney disease. N Engl J Med. 2009;361: 2019-32.

35 Bello NA, Lewis EF, Desai AS, Anand IS, Krum H, McMurray JJ, et al. Increased risk of stroke with darbepoetin alfa in anaemic heart failure patients with diabetes and chronic kidney disease. Eur J Heart Fail. 2015;17:1201-7.

36 Locatelli F, Hannedouche T, Fishbane S, Morgan Z, Oguey D, White WB. Cardiovascular safety and all-cause mortality of methoxy polyethylene glycol-epoetin beta and other erythropoiesis-stimulating agents in anemia of CKD. A randomized noninferiority trial. Clin J Am Soc Nephrol. 2019;14:1701-10.

37 Hahn D, Cody JD, Hodson EM. Frequency of administration of erythropoiesis-stimulating agents for the anaemia of end-stage kidney disease in dialysis patients. Cochrane Database Syst Rev. 2014:Cd003895.

38 Wilhelm-Leen ER, Winkelmayer WC. Mortality risk of darbepoetin alfa versus epoetin alfa in patients with CKD: systematic review and meta-analysis. Am J Kidney Dis. 2015;66: 69-74.

39 Amato L, Addis A, Saulle R, Trotta F, Mitrova Z, Davoli M. Comparative efficacy and safety in ESA biosimilars vs. originators in adults with chronic kidney disease: a systematic review and meta-analysis. J Nephrol. 2018;31: 321-32.

40 Minutolo R, Garofalo C, Chiodini P, Aucella F, Del Vecchio L, Locatelli F, et al. Types of erythropoiesis-stimulating agents and risk of end-stage kidney disease and death in patients with non-dialysis chronic kidney disease. Nephrol Dial Transplant. 2021;36(2): 267-74.

41 Sakaguchi Y, Hamano T, Wada A, Masakane I. Types of erythropoietin-stimulating agents and mortality among patients undergoing hemodialysis. J Am Soc Nephrol. 2019;30:103748.

42 Babitt JL, Lin HY. Mechanisms of anemia in CKD. J Am Soc Nephrol. 2012;23:1631-4.

43 Ganz T, Nemeth E. Iron balance and the role of hepcidin in chronic kidney disease. Semin Nephrol. 2016;36:87-93. 
44 Gafter-Gvili A, Schechter A, Rozen-Zvi B. Iron deficiency anemia in chronic kidney disease. Acta Haematol. 2019;142(1):44-50.

45 Nemeth E, Valore EV, Territo M, Schiller G, Lichtenstein A, Ganz T. Hepcidin, a putative mediator of anemia of inflammation, is a type II acute-phase protein. Blood. 2003;101: 2461-3.

46 Nemeth E, Rivera S, Gabayan V, Keller C, Taudorf S, Pedersen BK, et al. IL-6 mediates hypoferremia of inflammation by inducing the synthesis of the iron regulatory hormone hepcidin. J Clin Invest. 2004;113:1271-6.

47 Kalantar-Zadeh K, Höffken B, Wünsch H, Fink H, Kleiner M, Luft FC. Diagnosis of iron deficiency anemia in renal failure patients during the post-erythropoietin era. Am J Kidney Dis. 1995;26:292-9.

48 Babitt JL, Lin HY. Molecular mechanisms of hepcidin regulation: implications for the anemia of CKD. Am J Kidney Dis. 2010;55:726-41.

49 Pagani A, Nai A, Silvestri L, Camaschella C. Hepcidin and anemia: a tight relationship. Front Physiol. 2019;10:1294-4.

50 Macdougall IC, White C, Anker SD, Bhandari S, Farrington K, Kalra PA, et al. Intravenous iron in patients undergoing maintenance hemodialysis. N Engl J Med. 2019;380:447-58.

51 Lee SW, Kim JM, Lim HJ, Hwang YH, Kim SW, Chung W, et al. Serum hepcidin may be a novel uremic toxin, which might be related to erythropoietin resistance. Sci Rep. 2017;7: 4260.

52 Petruliene K, Ziginskiene E, Kuzminskis V, Nedzelskiene I, Bumblyte IA. Hepcidin serum levels and resistance to recombinant human erythropoietin therapy in hemodialysis patients. Medicina. 2017;53:90-100.

53 Malyszko J, Malyszko JS, Mysliwiec M. Hyporesponsiveness to erythropoietin therapy in hemodialyzed patients: potential role of prohepcidin, hepcidin, and inflammation. Ren Fail. 2009;31:544-8.

54 Yilmaz I, Ozkok A, Kostek O, Kolukısa A, Duran I, Odabaş AR, et al. C-reactive protein but not hepcidin, NGAL and transferrin determines the ESA resistance in hemodialysis patients. Ren Fail. 2016;38:89-95.

55 Santos EJF, Hortegal EV, Serra HO, Lages JS, Salgado-Filho N, Dos Santos AM. Epoetin alfa resistance in hemodialysis patients with chronic kidney disease: a longitudinal study. Braz J Med Biol Res. 2018;51:e7288.

56 El Sewefy DA, Farweez BA, Behairy MA, Yassin NR. Impact of serum hepcidin and inflammatory markers on resistance to erythropoiesis-stimulating therapy in haemodialysis patients. Int Urol Nephrol. 2019;51:325-34.

57 Panichi V, Rosati A, Bigazzi R, Paoletti S, Mantuano E, Beati S, et al. Anaemia and resistance to erythropoiesis-stimulating agents as prognostic factors in haemodialysis patients: results from the RISCAVID study. Nephrol Dial Transplant. 2011;26:2641-8.

58 Karaboyas A, Morgenstern H, Fleischer NL, Vanholder RC, Dhalwani NN, Schaeffner E, et al. Inflammation and erythropoiesis-stim- ulating agent response in hemodialysis patients: a Self-matched Longitudinal Study of anemia management in the dialysis outcomes and Practice Patterns Study (DOPPS). Kidney Med. 2020;2:286-96.

59 Robinson BM, Akizawa T, Jager KJ, Kerr PG, Saran R, Pisoni RL. Factors affecting outcomes in patients reaching end-stage kidney disease worldwide: differences in access to renal replacement therapy, modality use, and haemodialysis practices. Lancet. 2016;388:294-306.

60 Sanghani NS, Haase VH. Hypoxia-inducible factor activators in renal anemia: current clinical experience. Adv Chronic Kidney Dis. 2019;26:253-66.

61 Locatelli F, Fishbane S, Block GA, Macdougall IC. Targeting hypoxia-inducible factors for the treatment of anemia in chronic kidney disease patients. Am J Nephrol. 2017;45:187-99.

62 La Ferla K, Reimann C, Jelkmann W, HellwigBürgel T. Inhibition of erythropoietin gene expression signaling involves the transcription factors GATA-2 and NF-kappaB. FASEB J. 2002;16:1811-3.

63 Icardi A, Paoletti E, De Nicola L, Mazzaferro S, Russo R, Cozzolino M. Renal anaemia and EPO hyporesponsiveness associated with vitamin D deficiency: the potential role of inflammation. Nephrol Dial Transplant. 2013; 28:1672-9.

64 Jha V, Garcia-Garcia G, Iseki K, Li Z, Naicker S, Plattner B, et al. Chronic kidney disease: global dimension and perspectives. Lancet. 2013;382:260-72.

65 Solak Y, Afsar B, Vaziri ND, Aslan G, Yalcin $\mathrm{CE}$, Covic A, et al. Hypertension as an autoimmune and inflammatory disease. Hypertens Res. 2016;39:567-73.

66 Furman D, Campisi J, Verdin E, Carrera-Bastos P, Targ S, Franceschi C, et al. Chronic inflammation in the etiology of disease across the life span. Nat Med. 2019;25:1822-32.

67 Niewczas MA, Pavkov ME, Skupien J, Smiles A, Md Dom ZI, Wilson JM, et al. A signature of circulating inflammatory proteins and development of end-stage renal disease in diabetes. Nat Med. 2019;25:805-13.

68 Goodman WG, Quarles LD. Development and progression of secondary hyperparathyroidism in chronic kidney disease: lessons from molecular genetics. Kidney Int. 2008;74: 276-88.

69 Cunningham J, Locatelli F, Rodriguez M. Secondary hyperparathyroidism: pathogenesis, disease progression, and therapeutic options. Clin J Am Soc Nephrol. 2011;6:913-21.

70 Hedgeman E, Lipworth L, Lowe K, Saran R, Do $\mathrm{T}$, Fryzek J. International burden of chronic kidney disease and secondary hyperparathyroidism: a systematic review of the literature and available data. Int J Nephrol. 2015;2015:184321.

71 Sliem H, Tawfik G, Moustafa F, Zaki H. Relationship of associated secondary hyperparathyroidism to serum fibroblast growth factor-23 in end stage renal disease: a case-control study. Indian J Endocrinol Metab. 2011;15:105-9.
72 Chen L, Ling YS, Lin CH, He JX, Guan TJ. High dose ESAs are associated with high iPTH levels in hemodialysis patients with end-stage kidney disease: a retrospective analysis. Front Public Health. 2015;3:258.

73 Kalantar-Zadeh K, Lee GH, Miller JE, Streja E, Jing J, Robertson JA, et al. Predictors of hyporesponsiveness to erythropoiesis-stimulating agents in hemodialysis patients. Am J Kidney Dis. 2009;53:823-34.

74 Tanaka M, Komaba H, Fukagawa M. Emerging association between parathyroid hormone and anemia in hemodialysis patients. Ther Apher Dial. 2018;22:242-5.

75 Albitar S, Genin R, Fen-Chong M, Serveaux MO, Schohn D, Chuet C. High-dose alfacalcidol improves anaemia in patients on haemodialysis. Nephrol Dial Transplant. 1997; 12:514-8

76 Goicoechea M, Vazquez MI, Ruiz MA, Gomez-Campdera F, Perez-García R, Valderrábano F. Intravenous calcitriol improves anaemia and reduces the need for erythropoietin in haemodialysis patients. Nephron. 1998;78:23-7.

77 Aucella F, Scalzulli RP, Gatta G, Vigilante M, Carella AM, Stallone C. Calcitriol increases burst-forming unit-erythroid proliferation in chronic renal failure. A synergistic effect with r-HuEpo. Nephron Clin Pract. 2003;95:c121-7.

78 Usui T, Zhao J, Fuller DS, Hanafusa N, Hasegawa T, Fujino H, et al. Association of erythropoietin resistance and fibroblast growth factor 23 in dialysis patients: results from the Japanese Dialysis Outcomes and Practice Patterns Study. Nephrology. 2020;26: 46-53.

79 Kidney Disease Improving Global Outcomes (KDIGO) Blood Pressure Work Group. KDIGO clinical practice guidelines for the management of blood pressure in chronic kidney disease. Kidney Int Suppl. 2012;2:337-414.

80 Hou FF, Zhang X, Zhang GH, Xie D, Chen PY, Zhang WR, et al. Efficacy and safety of benazepril for advanced chronic renal insufficiency. N Engl J Med. 2006;354:131-40.

81 Hsu TW, Liu JS, Hung SC, Kuo KL, Chang YK, Chen YC, et al. Renoprotective effect of renin-angiotensin-aldosterone system blockade in patients with predialysis advanced chronic kidney disease, hypertension, and anemia. JAMA Intern Med. 2014;174:34754.

82 Pugh D, Gallacher PJ, Dhaun N. Management of hypertension in chronic kidney disease. Drugs. 2019;79:365-79.

83 Samavat S, Nafar M, Khoshdel A, AlipourAbedi B. Factors contributing to erythropoietin hyporesponsiveness among hemodialysis patients: a cross-sectional multicenter study. Nephro-Urol Monthly. 2017;9:e45003.

84 Winnicki W, Prehslauer A, Kletzmayr J, Herkner H, Sunder-Plassmann G, Brunner $\mathrm{M}$, et al. Lisinopril pharmacokinetics and erythropoietin requirement in haemodialysis patients. Eur J Clin Invest. 2012;42:1087-93. 
85 Rossert J, Gassmann-Mayer C, Frei D, McClellan W. Prevalence and predictors of epoetin hyporesponsiveness in chronic kidney disease patients. Nephrol Dial Transplant. 2007;22:794-800.

86 Johnson DW, Pascoe EM, Badve SV, Dalziel $\mathrm{K}$, Cass A, Clarke $\mathrm{P}$, et al. A randomized, placebo-controlled trial of pentoxifylline on erythropoiesis-stimulating agent hyporesponsiveness in anemic patients with CKD: the handling erythropoietin resistance with oxpentifylline (HERO) trial. Am J Kidney Dis. 2015;65:49-57.

87 Zhang L, Coombes J, Pascoe EM, Badve SV, Dalziel K, Cass A, et al. The effect of pentoxifylline on oxidative stress in chronic kidney disease patients with erythropoiesis-stimulating agent hyporesponsiveness: sub-study of the HERO trial. Redox Rep. 2016;21:14-23.

88 Gummer J, Trengove R, Pascoe EM, Badve SV, Cass A, Clarke P, et al. Association between serum hepcidin-25 and primary resistance to erythropoiesis-stimulating agents in chronic kidney disease: a secondary analysis of the HERO trial. Nephrology. 2017;22:54854.

89 Chiang CK, Yang SY, Peng YS, Hsu SP, Pai MF, Huang JW, et al. Atorvastatin increases erythropoietin-stimulating agent hyporesponsiveness in maintenance hemodialysis patients: role of anti-inflammation effects. Am J Nephrol. 2009;29:392-7.

90 Koc M, Dogan C, Arinsoy T, Tonbul Z, Ayli $\mathrm{D}$, Cirit $\mathrm{M}$, et al. Statin use is associated with lower inflammation and erythropoietin responsiveness index in hemodialysis patients. Hemodial Int. 2011;15:366-73.

91 Hasegawa T, Zhao J, Fuller DS, Bieber B, Zee J, Morgenstern H, et al. Erythropoietin hyporesponsiveness in dialysis patients: possible role of statins. Am J Nephrol. 2017;46:11-7.

92 Sui Z, Wang M, Zuo L. Statin therapy and erythropoiesis-stimulating agent hyporesponsiveness in patients with nondialysis chronic kidney disease: a retrospective study in Beijing, China. Medicine (Baltimore). 2019;98:e13981.

93 Kalantar-Zadeh K, Ikizler TA, Block G, Avram MM, Kopple JD. Malnutrition-inflammation complex syndrome in dialysis patients: causes and consequences. Am J Kidney Dis. $2003 ; 42: 864-81$.

94 Nassar GM, Fishbane S, Ayus JC. Occult infection of old nonfunctioning arteriovenous grafts: a novel cause of erythropoietin resistance and chronic inflammation in hemodialysis patients. Kidney Int Suppl. 2002;80:49-54.

95 Roberts TL, Obrador GT, St Peter WL, Pereira BJ, Collins AJ. Relationship among catheter insertions, vascular access infections, and anemia management in hemodialysis patients. Kidney Int. 2004;66:2429-36.

96 Ifudu O, Feldman J, Friedman EA. The intensity of hemodialysis and the response to erythropoietin in patients with end-stage renal disease. N Engl J Med. 1996;334:4205.
97 Bonforte G, Grillo P, Zerbi S, Surian M. Improvement of anemia in hemodialysis patients treated by hemodiafiltration with high-volume on-line-prepared substitution fluid. Blood Purif. 2002;20:357-63.

98 Bowry SK, Gatti E. Impact of hemodialysis therapy on anemia of chronic kidney disease: the potential mechanisms. Blood Purif. 2011;32:210-9.

99 Panichi V, Scatena A, Rosati A, Giusti R, Ferro G, Malagnino E, et al. High-volume online haemodiafiltration improves erythropoiesisstimulating agent (ESA) resistance in comparison with low-flux bicarbonate dialysis: results of the REDERT study. Nephrol Dial Transplant. 2015;30:682-9.

100 Marcelli D, Bayh I, Merello JI, Ponce P, Heaton A, Kircelli F, et al. Dynamics of the erythropoiesis stimulating agent resistance index in incident hemodiafiltration and high-flux hemodialysis patients. Kidney Int. 2016;90:192-202.

101 Sitter T, Bergner A, Schiffl H. Dialysate related cytokine induction and response to recombinant human erythropoietin in haemodialysis patients. Nephrol Dial Transplant. 2000;15:1207-11.

102 Hsu PY, Lin CL, Yu CC, Chien CC, Hsiau TG, Sun TH, et al. Ultrapure dialysate improves iron utilization and erythropoietin response in chronic hemodialysis patients: a prospective cross-over study. J Nephrol. 2004;17:693-700.

103 Tessitore N, Poli A, Bedogna V, Corazza L, Campostrini N, Atti M, et al. A single dialysis session of hemodiafiltration with sorbent-regenerated endogenous ultrafiltrate reinfusion (HFR) removes hepcidin more efficiently than bicarbonate hemodialysis: a new approach to containing hepcidin burden in dialysis patients? J Nephrol. 2018; 31(2):297-306.

104 Jansz TT, Özyilmaz A, Grooteman MPC, Hoekstra T, Romijn M, Blankestijn PJ, et al. Long-term clinical parameters after switching to nocturnal haemodialysis: a Dutch propensity-score-matched cohort study comparing patients on nocturnal haemodialysis with patients on three-times-a-week haemodialysis/haemodiafiltration. BMJ Open. 2018;8:e019900.

105 Nakanishi T, Kuragano T. Potential hazards of recent trends in liberal iron use for renal anemia. Clin Kidney J. 2021;14(1):59-69.

106 Haase VH. Hypoxic regulation of erythropoiesis and iron metabolism. Am J Physiol Renal Physiol. 2010;299:F1-13.

107 Kaplan JM, Sharma N, Dikdan S. Hypoxiainducible factor and its role in the management of anemia in chronic kidney disease. Int J Mol Sci. 2018;19:389.

108 Ehrismann D, Flashman E, Genn DN, Mathioudakis N, Hewitson KS, Ratcliffe PJ, et al. Studies on the activity of the hypoxia-inducible-factor hydroxylases using an oxygen consumption assay. Biochem J. 2007;401: 227-34.
109 Kapitsinou PP, Liu Q, Unger TL, Rha J, Davidoff $\mathrm{O}$, Keith $\mathrm{B}$, et al. Hepatic HIF-2 regulates erythropoietic responses to hypoxia in renal anemia. Blood. 2010;116:3039-48.

110 Minamishima YA, Kaelin WG Jr. Reactivation of hepatic EPO synthesis in mice after PHD loss. Science. 2010;329:407.

111 Dhillon S. Daprodustat: first approval. Drugs. 2020;80:1491-7.

112 Markham A. Vadadustat: first approval. Drugs. 2020;80:1365-71.

113 Markham A. Enarodustat: first approval Drugs. 2021;81(1):169-74.

114 New Drug Approvals in Japan. 2021. Available from: https://www.genome.jp/kegg/ drug/br08318.html.

115 Besarab A, Chernyavskaya E, Motylev I, Shutov E, Kumbar LM, Gurevich K, et al. Roxadustat (FG-4592): correction of anemia in incident dialysis patients. J Am Soc Nephrol. 2016;27:1225-33.

116 Provenzano R, Besarab A, Sun CH, Diamond SA, Durham JH, Cangiano JL, et al. Oral hypoxia-inducible factor prolyl hydroxylase inhibitor roxadustat (FG-4592) for the treatment of anemia in patients with CKD. Clin J Am Soc Nephrol. 2016;11:98291.

117 Provenzano R, Besarab A, Wright S, Dua S Zeig S, Nguyen P, et al. Roxadustat (FG4592) versus epoetin alfa for anemia in patients receiving maintenance hemodialysis: a phase 2, randomized, 6- to 19-week, openlabel, active-comparator, dose-ranging, safety and exploratory efficacy study. Am J Kidney Dis. 2016;67:912-24.

118 Chen N, Qian J, Chen J, Yu X, Mei C, Hao C, et al. Phase 2 studies of oral hypoxia-inducible factor prolyl hydroxylase inhibitor FG4592 for treatment of anemia in China. Nephrol Dial Transplant. 2017;32:1373-86.

119 Akizawa T, Ueno M, Shiga T, Reusch M. Oral roxadustat three times weekly in ESAnaive and ESA-converted patients with anemia of chronic kidney disease on hemodialysis: results from two phase 3 studies. Ther Apher Dial. 2019;24:628-41.

120 Chen N, Hao C, Liu BC, Lin H, Wang C, Xing C, et al. Roxadustat treatment for anemia in patients undergoing long-term dialysis. N Engl J Med. 2019;381:1011-22.

121 Chen N, Hao C, Peng X, Lin H, Yin A, Hao $\mathrm{L}$, et al. Roxadustat for anemia in patients with kidney disease not receiving dialysis. $\mathrm{N}$ Engl J Med. 2019;381:1001-10.

122 Akizawa T, Iwasaki M, Yamaguchi Y, Majikawa Y, Reusch M. Phase 3, randomized, double-blind, active-comparator (Darbepoetin Alfa) Study of oral roxadustat in CKD patients with anemia on hemodialysis in Japan. J Am Soc Nephrol. 2020;31:1628-39.

123 Akizawa T, Otsuka T, Reusch M, Ueno M Intermittent oral dosing of roxadustat in peritoneal dialysis chronic kidney disease patients with anemia: a randomized, phase 3, multicenter, open-label study. Ther Apher Dial. 2020;24:115-25. 
124 Coyne DW, Roger SD, Shin SK, Kim SG, Cadena AA, Moustafa MA, et al. Roxadustat for CKD-related anemia in non-dialysis patients. Kidney Int Rep. 2021;6(3):624-35.

125 Fishbane S, El-Shahawy MA, Pecoits-Filho R, Van BP, Houser MT, Frison L, et al. Roxadustat for treating anemia in patients with CKD not on dialysis: results from a randomized phase 3 study. J Am Soc Nephrol. 2021; 32(3):737-55.

126 Provenzano R, Shutov E, Eremeeva L, Korneyeva S, Poole L, Saha G, et al. Roxadustat for anemia in patients with end-stage renal disease incident to dialysis. Nephrol Dial Transplant. 2021;gfab051.

127 Shutov E, Sułowicz W, Esposito C, Tataradze A, Andric B, Reusch M, et al. Roxadustat for the treatment of anemia in chronic kidney disease patients not on dialysis: a phase 3 , randomized, doubleblind, placebo-controlled study (ALPS). Nephrol Dial Transplant. 2021;gfab057.

128 Brigandi RA, Johnson B, Oei C, Westerman M, Olbina G, de Zoysa J, et al. A novel hypoxia-inducible factor-prolyl hydroxylase inhibitor (GSK1278863) for anemia in CKD: a 28-day, phase $2 \mathrm{~A}$ randomized trial. Am J Kidney Dis. 2016;67:861-71.

129 Holdstock L, Meadowcroft AM, Maier R, Johnson BM, Jones D, Rastogi A, et al. Fourweek studies of oral hypoxia-inducible factor-prolylhydroxylaseinhibitorGSK1278863 for treatment of anemia. J Am Soc Nephrol. 2016;27:1234-44.

130 Cizman B, Sykes AP, Paul G, Zeig S, Cobitz AR. An exploratory study of daprodustat in erythropoietin-hyporesponsive subjects. Kidney Int Rep. 2018;3:841-50.

131 Holdstock L, Cizman B, Meadowcroft AM, Biswas N, Johnson BM, Jones D, et al. Daprodustat for anemia: a 24-week, open-label, randomized controlled trial in participants with chronic kidney disease. Clin Kidney J. 2019;12:129-38.

132 Meadowcroft AM, Cizman B, Holdstock L, Biswas N, Johnson BM, Jones D, et al. Daprodustat for anemia: a 24-week, open-label, randomized controlled trial in participants on hemodialysis. Clin Kidney J. 2019;12: 139-48.

133 Akizawa T, Nangaku M, Yonekawa T, Okuda N, Kawamatsu S, Onoue T, et al. Efficacy and safety of daprodustat compared with darbepoetin alfa in Japanese hemodialysis patients with anemia: a randomized, double-blind, phase 3 trial. Clin J Am Soc Nephrol. 2020;15:1155-65.

134 Tsubakihara Y, Akizawa T, Nangaku M, Onoue T, Yonekawa T, Matsushita $\mathrm{H}$, et al. A 24-week anemia correction study of daprodustat in Japanese dialysis patients. Ther Apher Dial. 2020;24:108-14.

135 Nangaku M, Hamano T, Akizawa T, Tsubakihara Y, Nagai R, Okuda N, et al. Daprodustat compared with epoetin beta pegol for anemia in Japanese patients not on dialysis: a 52-week randomized open-label phase 3 trial. Am J Nephrol. 2021;52(1):2635.

136 Parmar DV, Kansagra KA, Patel JC, Joshi SN, Sharma NS, Shelat AD, et al. Outcomes of desidustat treatment in people with anemia and chronic kidney disease: a Phase 2 Study. Am J Nephrol. 2019;49:470-8.

137 Akizawa T, Nangaku M, Yamaguchi T, Arai M, Koretomo R, Maeda K, et al. Enarodustat, conversion and maintenance therapy for anemia in hemodialysis patients: a randomized, placebo-controlled phase $2 \mathrm{~b}$ trial followed by long-term trial. Nephron. 2019; 143:77-85.

138 Akizawa T, Nangaku M, Yamaguchi T, Arai M, Koretomo R, Matsui A, et al. A placebocontrolled, randomized trial of enarodustat in patients with chronic kidney disease followed by long-term trial. Am J Nephrol. 2019;49:165-74

139 Akizawa T, Macdougall IC, Berns JS, Yamamoto $\mathrm{H}$, Taguchi M, Iekushi $\mathrm{K}$, et al. Iron regulation by molidustat, a daily oral hypoxia-inducible factor prolyl hydroxylase inhibitor, in patients with chronic kidney disease. Nephron. 2019;143:243-54.

140 Macdougall IC, Akizawa T, Berns JS, Bernhardt T, Krueger T. Effects of molidustat in the treatment of anemia in CKD. Clin J Am Soc Nephrol. 2019;14:28-39.

141 Akizawa T, Iekushi K, Matsuda Y, Nobori K, Taguchi M, Yamamoto H. P1868 to investigate the efficacy and safety of molidustat in non-dialysis patients with renal anemia who are treated with erythropoiesis-stimulating agents: Miyabi Nd-M. Nephrol Dial Transplant. 2020;35:2179.

142 Akizawa T, Iekushi K, Matsuda Y, Nobori K, Taguchi M, Yamamoto H. P1866 to investigate the efficacy and safety of molidustat in non-dialysis patients with renal anemia who are not treated with erythropoiesis-stimulating agents: Miyabi Nd-C. Nephrol Dial Transplant. 2020;35:2177.

143 Akizawa T, Nobori K, Matsuda Y, Hayashi Y, Hayasaki T, Yamamoto H. Molidustat for anemia correction in Japanese patients undergoing hemodialysis: a single-arm, phase 3 study. Ther Apher Dial. 2021.

144 Pergola PE, Spinowitz BS, Hartman CS, Maroni BJ, Haase VH. Vadadustat, a novel oral HIF stabilizer, provides effective anemia treatment in nondialysis-dependent chronic kidney disease. Kidney Int. 2016;90:111522.

145 Martin ER, Smith MT, Maroni BJ, Zuraw QC, deGoma EM. Clinical trial of vadadustat in patients with anemia secondary to stage 3 or 4 chronic kidney disease. Am J Nephrol. 2017;45:380-8.

146 Haase VH, Chertow GM, Block GA, Pergola PE, deGoma EM, Khawaja Z, et al. Effects of vadadustat on hemoglobin concentrations in patients receiving hemodialysis previously treated with erythropoiesis-stimulating agents. Nephrol Dial Transplant. 2019;34: 90-9.
147 Nangaku M, Farag YMK, deGoma E, Luo W, Vargo D, Khawaja Z. Vadadustat, an oral hypoxia-inducible factor prolyl hydroxylase inhibitor, for treatment of anemia of chronic kidney disease: two randomized Phase 2 trials in Japanese patients. Nephrol Dial Transplant. 2020.

148 Nangaku M, Kondo K, Takabe S, Ueta K, Kaneko G, Otsuka M, et al. Vadadustat for anemia in chronic kidney disease patients on peritoneal dialysis: a phase 3 open-label study in Japan. Ther Apher Dial. 2020.

149 Nangaku M, Kondo K, Ueta K, Kokado Y, Kaneko G, Matsuda H, et al. Efficacy and safety of vadadustat compared with darbepoetin alfa in Japanese anemic patients on hemodialysis: a phase 3 , multicenter, randomized, double-blind study. Nephrol Dial Transplant. 2021 Feb 26:gfab055.

150 Wen T, Zhang X, Wang Z, Zhou R. Hypoxiainducible factor prolyl hydroxylase inhibitors in patients with renal anemia: a metaanalysis of randomized trials. Nephron. 2020;144:572-82.

151 Pecoits-Filho R, Chan DT, Hardy E, Yu KP, Fishbane S. Roxadustat treatment results in consistent improvements in hemoglobin $(\mathrm{Hb})$ vs. placebo: an analysis of three multinational randomized clinical trials in patients with non-dialysis-dependent CKD (NDD-CKD) [TH-OR05]. J Am Soc Nephrol. 2020;31:2.https://www.asn-online.org/education/kidneyweek/archives/ KW20Abstracts.pdf.

152 Rastogi A, Pecoits-Filho R, Fishbane S, Little DJ, Hardy E, Yu KHP, et al. Roxadustat treatment corrects anemia to hemoglobin $(\mathrm{Hb})$ values $\geq 10 \mathrm{~g} / \mathrm{dL}$ in the majority of patients with non-dialysis-dependent chronic kidney disease (NDD-CKD) [PO0264]. Am Soc Nephrol. 2020;31:133.https://www. asn-online.org/education/kidneyweek/archives/KW20Abstracts.pdf.

153 Eckardt KU; INNO2VATE Author Group. Global phase 3 clinical trials of vadadustat vs. darbepoetin alfa for treatment of anemia in patients with dialysis-dependent CKD [TH-OR01]. J Am Soc Nephrol. 2020;31:1. https://www.asn-online.org/education/ kidneyweek/2020/program-abstract. aspx? controlId $=3441404$.

154 El-Shahawy MA, Roger SD, Manllo-Karim R, Pola M, Tham S, Szczech L, et al. Roxadustat increases hemoglobin in anemic dialysis-dependent (DD) CKD patients independent of inflammation [PO0265]. J Am Soc Nephrol. 2020;31:133.https://www.asn-online.org/education/kidneyweek/2020/program-abstract.aspx? controlId $=3445033$.

155 Pollock CA, Roger SD, Manllo-Karim R, Pola M, Tham S, Yu KHP, et al. Roxadustat increases hemoglobin in anemic non-dialysis-dependent (NDD) CKD patients independent of inflammation. J Am Soc Nephrol. 2020;31:132-3. https://ash.confex.com/ash/2020/webprogram $/ \mathrm{Pa}$ per137493.html. 
156 Hashiguchi J, Funakoshi S, Sawase K, Kawazu T, Hayashi K, Yamaguchi K, et al. Effects of roxadustat treatment on serum parathyroid hormone $(\mathrm{PTH})$ in hemodialysis patients with erythropoiesis-stimulating agent (ESA) resistant anemia [PO0266]. J Am Soc Nephrol. 2020;31:133-4.https://www.asnonline.org/education/kidneyweek/2020/ program-abstract.aspx? controlId=3443332.

157 Funakoshi S, Hashiguchi J, Sawase K, Kawazu T, Kitamura M, Hayashi K, et al. Role of roxadustat in improving erythropoiesisstimulating agent (ESA)-resistant anemia in patients on maintenance hemodialysis [PO1030]. J Am Soc Nephrol. 2020;31:352. https: //www.asn-online.org/education/kidneyweek/2020/program-abstract. aspx? controlId $=3444559$.

158 Yap DYH, McMahon LP, Hao CM, Hu N, Okada H, Suzuki Y, et al. Recommendations by the Asian Pacific Society of Nephrology (APSN) on the appropriate use of HIF-PH inhibitors. Nephrology. 2021;26(2):105-18.

159 Astellas Pharma Europe BV. A Phase 3, Randomized, Open-Label, Active-Controlled Study to Evaluate the Efficacy and Safety of Roxadustat in the Maintenance Treatment of Anemia in End Stage Renal Disease Patients on Stable Dialysis. European Medicines Agency; 2019. Available from: https:// www.clinicaltrialsregister.eu/ctr-search/tri$\mathrm{al} / 2013-001497-16 /$ results.

160 Akebia Therapeutics Announces Top-Line Results from its PRO2TECT Global Phase 3 Program of Vadadustat for Treatment of Anemia Due to Chronic Kidney Disease in Adult Patients Not on Dialysis. Akebia Therapeutics; 2020. Available from: https:// ir.akebia.com/news-releases/news-releasedetails/akebia-therapeutics-announces-topline-results-its-pro2tect.
161 Liu J, Wei Q, Guo C, Dong G, Liu Y, Tang C, et al. Hypoxia, HIF, and associated signaling networks in chronic kidney disease. Int J Mol Sci. 2017;18:950.

162 Chappell JC, Payne LB, Rathmell WK. Hypoxia, angiogenesis, and metabolism in the hereditary kidney cancers. J Clin Invest. 2019;129:442-51.

163 Mustafa R, Bloudek L, Fox G, Carlson JJ, Campbell JD, Agboola F, et al. Treatments for anemia in chronic kidney disease: effectiveness and value; final evidence report. Inst Clin Econ Rev. 2021.https://icer.org/assessment/anemia-in-chronic-kidney-disease-2021/\#timeline.

164 van Eijk LT, John AS, Schwoebel F, Summo L, Vauléon S, Zöllner S, et al. Effect of the antihepcidin Spiegelmer lexaptepid on inflammation-induced decrease in serum iron in humans. Blood. 2014;124:2643-6.

165 Boyce M, Warrington S, Cortezi B, Zöllner S, Vauléon S, Swinkels DW, et al. Safety, pharmacokinetics and pharmacodynamics of the anti-hepcidin Spiegelmer lexaptepid pegol in healthy subjects. Br J Pharmacol. 2016;173:1580-8.

166 Sheetz M, Barrington P, Callies S, Berg PH, McColm J, Marbury T, et al. Targeting the hepcidin-ferroportin pathway in anaemia of chronic kidney disease. Br J Clin Pharmacol. 2019;85:935-48.

167 van der Weerd NC, Grooteman MP, Bots $\mathrm{ML}$, van den Dorpel MA, den Hoedt $\mathrm{CH}$, Mazairac AH, et al. Hepcidin-25 is related to cardiovascular events in chronic haemodialysis patients. Nephrol Dial Transplant. 2013;28:3062-71.

168 Oyelade T, Alqahtani J, Canciani G. Prognosis of COVID-19 in patients with liver and kidney diseases: an early systematic review and meta-analysis. Trop Med Infect Dis. 2020;5:80.
169 Shahid Z, Kalayanamitra R, McClafferty B, Kepko D, Ramgobin D, Patel R, et al. COVID-19 and older adults: what we know. J Am Geriatr Soc. 2020;68:926-9.

170 Cummings MJ, Baldwin MR, Abrams D, Jacobson SD, Meyer BJ, Balough EM, et al. Epidemiology, clinical course, and outcomes of critically ill adults with COVID-19 in New York City: a prospective cohort study. Lancet. 2020;395:1763-70.

171 Sonnweber T, Boehm A, Sahanic S, Pizzini A, Aichner M, Sonnweber B, et al. Persisting alterations of iron homeostasis in COVID-19 are associated with non-resolving lung pathologies and poor patients' performance: a prospective observational cohort study. Respir Res. 2020;21:276.

172 Li J, Li SX, Zhao LF, Kong DL, Guo ZY. Management recommendations for patients with chronic kidney disease during the novel coronavirus disease 2019 (COVID-19) epidemic. Chronic Dis Transl Med. 2020;6: 119-23.

173 Coronavirus Disease 2019 (COVID-19): Special considerations for patients on home dialysis. United States Centers for Disease Control and Prevention; 2020. Available from: https://www.cdc.gov/coronavirus/2019ncov/hcp/dialysis/home-dialysis.html.

174 Coronavirus Disease 2019 (COVID-19): People with Certain Medical Conditions. United States Centers for Disease Control and Prevention; 2020. Available from: https: //www.cdc.gov/coronavirus/2019-ncov/ need-extra-precautions/people-with-medical-conditions.html.

175 Fishbane S, Hirsch JS. Erythropoiesis-stimulating agent treatment in patients with $\mathrm{CO}$ VID-19. Am J Kidney Dis. 2020;76:303-5. 